\title{
O PODER LOCAL E O CORONELISMO NO PARANÁ1
}

\author{
Mônica Helena Harrich Silva Goulart ${ }^{2}$
}

- Enviado em 12/09/2015

- Aprovado em 10/10/2015

\section{RESUMO}

O presente artigo se propõe a analisar o fenômeno do coronelismo no estado do Paraná entre os anos de 1880 a 1930. Percebeu-se que o coronelismo paranaense ocorreu segundo a perspectiva de Vitor Nunes Leal, que o considera a partir da relação sistêmica de troca de favores entre os representantes do poder privado, os chamados coronéis (enfraquecidos), e o poder público, os governadores estaduais (cada vez mais fortalecidos). Para o coronel, a garantia de sua posição se dava pelo controle dos votos da população pobre e dependente, cuja maioria se encontrava no meio rural. São apresentados os elementos fundamentais para o entendimento de tal fenômeno através do mapeamento de suas estruturas formais, do arranjo do poder político partidário disciplinador e das práticas ilegais no momento das eleições, além da análise das trocas de favores que envolvia tal sistema. Para desenvolvimento da pesquisa, recorreu-se ao estudo de vários aspectos do tema: primeiramente, a discussão efetivamente teórica a respeito do próprio conceito de coronelismo, bem como a pesquisa empírica por meio de diversas fontes, como jornais, constituições estaduais e atas da Assembleia $^{3}$ Legislativa do Paraná.

Palavras-chave: Sistema Coronelista. Paraná. Primeira República.

\section{INTRODUÇÃO}

Acreditamos ser o tema do coronelismo ${ }^{4}$ por si só fundamental para a Sociologia, pois constituiu um dos eixos importantes para a compreensão da estrutura política e social do Brasil do fim do século XIX e início do século XX. Mesmo tendo alto grau de relevância na investigação sociológica, o Paraná (até o momento de 2004) não apresentava nenhuma obra específica que

1 Dissertação de Mestrado defendida em 2004. Versão completa disponível na Biblioteca Digital da UFPR: <http://dspace.c3sl.ufpr.br/dspace/handle/1884/11747>.

${ }^{2}$ Graduada em Ciências Sociais pela UFPR. Mestre em Sociologia, concentração em Sociologia Política, pela UFPR. Doutora em Sociologia, Linha Instituições e Poder, pela UFPR. Pós-doutoranda em Sociologia (UFPR) e Professora Adjunta do Departamento Acadêmico de Estudos Sociais - DAESO, da Universidade Tecnológica Federal do Paraná UTFPR.

${ }^{3}$ No Império chamava-se Assembleia Provincial, e na República, Congresso Legislativo.

${ }^{4} \mathrm{O}$ termo coronel é proveniente de um posto da Guarda Nacional, criada ainda no Império, no dia 10 de agosto de 1831 , e extinta em 1918, que tinha como objetivo principal coibir movimentos revolucionários e pressionar os grupos sociais conforme os interesses dos senhores de terras. Nesse contexto, eram os mandatários locais que ocupavam os principais postos e, com o passar do tempo, a patente de coronel deixou de ser exclusivamente uma designação militar para indicar também o poder político dos chefes locais que, na maioria das vezes, também eram proprietários locais. (LEAL, 1986). 
tratasse do tema, mas sim livros que discutiam de forma geral o assunto, concatenando-o com outras análises. De qualquer maneira, a presente pesquisa visa contribuir para o diálogo com estudos que analisam o poder local e o coronelismo em outros estados e, também, vislumbra dialogar com análises da dinâmica coronelista em municípios paranaenses específicos.

Se o objeto da pesquisa é o estudo do coronelismo no estado do Paraná, efetivamente durante a Primeira República, o objetivo é detectar a forma pela qual este fenômeno se estruturou durante o respectivo período, procurando responder, assim, algumas questões que são tomadas com caráter peculiar, tais como: quais as especificidades do coronelismo paranaense? O coronelismo no Paraná representou o enfraquecimento do poder local privado diante do poder público, o governo estadual? O cerceamento da autonomia municipal era o pano de fundo de sua legislação, tal como apresentava o Artigo 68 da Constituição Federal de 1891? Os partidos políticos existentes na época, fundamentalmente o Partido Republicano Federal (PRF - situacionista) e o Partido Republicano 5 (PR - oposicionista) além de, posteriormente, o Partido Republicano Paranaense, eram instrumentos que garantiam a prática coronelista? As eleições cumpriram, no Paraná, a mesma função que teve no restante do país de aglutinar votos segundo a vontade do coronel, através da fidelidade e dificuldade econômica da massa da população? As fraudes eleitorais eram mecanismos recorrentes que garantiam as eleições de determinados grupos? Enfim, esses aspectos definidores do sistema coronelista serão refletidos a partir da perspectiva teórica de Vitor Nunes Leal, na sua clássica obra Coronelismo, enxada e voto (1986), que o considera, sobretudo, como um sistema político.

\section{CORONELISMO: ASPECTOS TEÓRICOS E CONCEITUAIS}

Embora o termo coronelismo seja utilizado com frequência tanto no meio acadêmico quanto na literatura em geral e, aleatoriamente, até mesmo em vários veículos de comunicação, quando pensado no contexto do debate teórico, em particular na Sociologia, deve ser considerado a partir de perspectivas específicas e também inserido em um contexto histórico preciso.

No rol de estudos fundamentais, a obra de Nunes Leal demarca o coronelismo nas diversas regiões do Brasil. Nessa abordagem, o coronelismo é um sistema político que envolve o poder público e o poder privado em uma relação de cunho político a partir de um contexto social e

\footnotetext{
5 Antes de 1897 era chamado de Partido da União Republicana, ou somente de União Republicana. E o Partido Republicano Federal, era chamado de Partido Republicano. (GOULART, 2014).
} 
econômico específico, visto que os participantes se estendem desde a base da sociedade, os eleitores (na maioria, a população $\operatorname{rural}^{6}$ ), até o presidente da República, passando pela figura do coronel e pelo governador estadual.

Não se pode esquecer que a história político-administrativa do Brasil sempre foi sublinhada por relações firmadas entre a esfera pública e a privada ${ }^{7}$ Entretanto, é na Primeira República que essa relação se desenvolveu a partir do fortalecimento do poder público em detrimento do enfraquecimento do poder privado, pois o próprio contexto social, político e econômico criou condições favoráveis a essa prática. Mas, quais seriam, então, os aspectos fundamentais para se pensar o coronelismo enquanto sistema político a partir da visão de Vitor Nunes Leal?

Primeiro, a fraqueza do poder privado advindo de aspectos econômicos ${ }^{8}$ (dos coronéis) e, portanto, sua submissão ao poder público (representado pela figura do governador do estado, que surge com a Proclamação da República e a implantação do federalismo) através do cerceamento da autonomia municipal (firmada pela Constituição de 1891). Segundo, a pobreza da população do campo (derivada de uma estrutura agrária inadequada) que tem como mediador de sua situação precária o coronel, o qual acaba se prevalecendo do voto do indivíduo ${ }^{9}$, fácil de ser manipulado simplesmente por cumprir seu papel numa relação de dependência pessoal ${ }^{10}$ para com aquele que lhe fornece o pouco que possui. E, em terceiro, o coronelismo que, através do sufrágio universal, era propriamente a base funcional da política dos governadores $^{11}$, os quais justapostos

\footnotetext{
${ }^{6}$ Segundo Vitor Nunes Leal, mesmo em 1945 (época posterior ao período da presente análise) o eleitorado ainda se concentrava no campo, ou seja, $73 \%$ dos eleitores estavam no meio rural. No Paraná, a situação não era diferente, tomando como exemplo alguns municípios, em particular, a distribuição da população no perímetro urbano, se apresenta os seguintes dados: Campina Grande, 10\%; Campo Largo, 6,8\%; Castro, 4,6\%; Lapa, 15\%; São José dos Pinhais, 7,3 \%; e, São Mateus, com apenas 8,3\% da população vivendo no espaço urbano. (GOULART, 2004).

${ }^{7}$ Conferir discussão sobre patrimonialismo em Os Donos do Poder, de Raymundo Faoro (1991) e em José Maurício Domingues, Patrimonialismo e Neopatrimonialismo, na coletânea Corrupção: ensaios e críticas (2008).

${ }^{8}$ Em 1889 a elite campeira se encontrava em declínio. Com a República a erva mate assume importância econômica no estado, fazendo os descendentes da classe dominante dirigirem-se para este setor e, posteriormente, para a atividade madeireira. Mesmo assim, as atividades ervateiras e madeireiras sofreram dificuldades por parte da concorrência internacional e o pouco estímulo do governo federal, já que representavam pouco na balança de exportação. (GOULART, 2004).
}

9 A massa dos trabalhadores do campo sobrevivia de salários escassos, dependendo dos recursos dos coronéis, resultando num vínculo de dependência e de fidelidade. (LEAL, 1986; GOULART, 2004).

10 O fato de o voto ser obtido por meio de uma relação de fidelidade, de uma disposição em se votar na "indicação" do candidato do coronel como forma de retribuição, não se descarta os aspectos recorrentes ao uso da força. Em 1872, somente $16 \%$ dos brasileiros eram alfabetizados, em 1920, apenas 24\% sabiam ler e escrever. (CARVALHO, 2004).

${ }^{11}$ Mecanismo de apoio do governo federal aos governadores estaduais, ou seja, situacionismo político garantido pelos votos controlados nos currais eleitorais. (GOULART, 2004). 
determinavam a montagem do congresso federal e da eleição para Presidente da República e, do outro lado, essa relação de apoio eleitoral garantia determinado prestígio local e recursos ao chefe político, principalmente para aqueles que estavam sob suas ordens. Nas palavras de Leal:

Coronelismo, que é o sistema de reciprocidade: de um lado os chefes municipais e os coronéis, que conduzem magotes de eleitores como quem toca tropa de burros; de outro lado, a situação política dominante no Estado, que dispões do erário, dos empregos, dos favores e da força policial, que possui, em suma, o cofre das graças e o poder da desgraça. (LEAL, 1986, p. 43).

Em conformidade com o enfoque sistêmico do coronelismo, José Murilo de Carvalho, em Mandonismo, Coronelismo e Clientelismo: uma discussão conceitual ${ }^{12}$ (1997) enfatiza que tal arranjo se estabelece "para baixo", no sentido de que o coronel presta serviços ao governador do estado na medida em que garante as eleições nos municípios por meio do voto de cabresto, em meio ao vínculo de favores ${ }^{13}$ recebidos para que este tenha garantido seu prestígio político e econômico local; enquanto que da parte do governador, "para cima", é o apoio político e também eleitoral ao Presidente da República, que lhe garante a contrapartida de ter o domínio ${ }^{14}$ efetivo no estado.

Outro aspecto essencial para se entender o sistema coronelista é pensá-lo por meio da questão do município, o qual assume novos aspectos no contexto da República. Se na Colônia e Império $^{15}$ os indivíduos que controlavam o município o faziam por ter força política e também econômica perante os demais representantes do aparelho de Estado, com a República, os antigos coronéis, potentados locais, passam a ter seu poder cada vez mais limitado. Se o coronel se torna o agente político subordinado ao poder local, e consequentemente, subjugado às determinações do

\footnotetext{
12 Aponta elementos fundamentais dos respectivos termos no sentido de situá-los historicamente em seus devidos contextos e características, propondo que sejam pensados não como sinônimos, mas conceitos interligados. (CARVALHO, 1997).
}

${ }^{13}$ Os referidos favores se estabeleciam de toda ordem, não apenas em transferência de recursos econômicos, mas na nomeação de cargos públicos para os indivíduos de confiança do coronel como delegados, subdelegados, juízes e até mesmo professores. Afinal, tendo acesso às pessoas mais importantes do local, o controle do voto da população ficava mais fácil de ser garantido e, principalmente, a quase impossibilidade de se formar uma oposição bem-sucedida. (LEAL, 1986).

14 “Um mínimo de estabilidade do sistema exigia algum tipo de entendimento com os coronéis, ou parte deles, sendo de importância secundária que a contrapartida do coronel se concretize exclusivamente em votos. Bastava o apoio tácito, a não rebelião. Se tudo dependesse do voto, seria de se esperar uma luta maior por seu controle, com a consequência de que a participação eleitoral teria atingido proporções muito maiores do que os míseros $2 \%$ ou $3 \%$ da população. Com essa qualificação, a tese de Leal continua de pé”. (CARVALHO, 1997, p. 236).

${ }^{15}$ Para uma abordagem do contexto Imperial, Richard Graham, em Clientelismo e política no Brasil do século XIX (1997), traz uma análise do clientelismo no espaço da política do século XIX, compreendendo-o pela capacidade de "[...] preenchimento de cargos governamentais quanto à proteção de pessoas humildes, mesmo os trabalhadores agrícolas sem terra". (GRAHAM, 1997, p. 16). 
governo estadual, isso requer necessariamente uma ligação com os trâmites legais, legitimados pela Constituição de 1891, que transferiu aos estados a administração e os recursos municipais.

Neste sentido, Nunes Leal propõe que a fraqueza do coronel é resultado da delimitação de seus recursos econômicos e do cerceamento da autonomia municipal, a qual determinou que coubesse ao estado "cuidar" dos atributos municipais, como o repasse de verbas para controle das finanças e benfeitorias locais, do processo eleitoral, da nomeação de delegados e juízes, como também da nomeação ${ }^{16}$ de prefeitos (em casos específicos), e tudo que estaria confinado ao "peculiar interesse" de cada estado.

Do aspecto anterior, decorre outro elemento fundamental no que concerne à oposição política, pois esta posição é difícil de ser firmada no plano municipal justamente pelos inúmeros mecanismos ${ }^{17}$ (dispensados aos coronéis pelos governadores) de controle do processo eleitoral, podendo ser formais ou não. Afinal, quem fica na oposição é somente quem não pode ficar do lado da situação e suas respectivas possibilidades de obtenção de privilégios ${ }^{18}$.

Outra abordagem importante sobre o coronelismo provém de Maria Isaura Pereira de Queiroz, em $O$ coronelismo numa interpretação sociológica (1976), aproximando-o com outras práticas políticas, como o mandonismo e o clientelismo. Diferente de Vitor N. Leal e José Murilo de Carvalho, para a autora o fenômeno tem seus primórdios ainda no Império e o seu aprimoramento na Primeira República, pois afirma que os coronéis continuaram ${ }^{19}$ exercendo seus papéis de "mandões" na política de forma bastante expressiva mesmo depois de 1930. Segundo

\footnotetext{
${ }^{16}$ As Constituições do Paraná (1891, 1892 e 1927) deixavam clara a nomeação do prefeito da Capital, os demais seriam eleitos por meio do sufrágio universal. Todavia, a Assembleia Legislativa, em 1905, aprovou projeto de lei determinando que todos os prefeitos do Estado passariam a ser nomeados pelo governador e não mais eleitos pelo voto. Os jornais deixam de relatar eleições para o executivo municipal até meados da década de 1910. O referido projeto foi apresentado pelo deputado estadual João D. Pernetta, liderança parlamentar do governador Vicente Machado. (GOULART, 2014).
}

${ }^{17} \mathrm{O}$ fósforo era o eleitor que votava várias vezes em locais diferentes. As eleições "bico de pena" ocorriam quando as atas eram preenchidas irregularmente. (CARVALHO, 2014).

\footnotetext{
${ }^{18}$ Alguns municípios paranaenses também eram frutos de disputas políticas. Todavia, o que se buscava era o apoio do situacionismo e não o seu combate. Em outros casos, constata-se a alternância na ocupação das prefeituras e nas eleições para cadeiras na Assembleia Legislativa do Paraná - ALEP (chamada na época de Congresso Legislativo do Estado do Paraná. No fim das contas, "[...] é pela comprovação de possuir a maioria do eleitorado no município que qualquer facção local mais se credencia às preferências da situação estadual”. (LEAL, 1986, p. 49).

${ }^{19}$ Quando se pensa a restrição de tal entre os anos 1889-1930, segundo a dimensão sistêmica, correlacionam-se todos os elementos que o sustentam, ou seja, aspectos que estão presentes somente no período mencionado, haja vista que após 1930, por exemplo, a figura de governador estadual passa a ser substituída pelo interventor estadual (submetendo-se efetivamente ao Presidente Getúlio Vargas e à sua centralização político-administrativa e, na maioria das vezes, destituído de vínculos políticos com os representantes locais), além do fato da população se deslocar cada vez mais para os centros urbanos, num crescente do processo de industrialização, de alfabetização (ainda que num ritmo muito mais lento) e, também, com a massificação dos próprios meios de comunicação, que acabaram por desativar a importância e função do coronel.
} 
Maria Isaura, a clientela do coronel não era representada apenas por pessoas que dependiam economicamente deste, pois representavam diversos "escalões sociais", desde os que não possuíam nenhum recurso financeiro, até mesmo aqueles que detinham algum bem.

Todo coronel era integrante em nível elevado de um grupo de parentela ${ }^{20}$ mais ou menos vasto; e os grandes coronéis se constituíam realmente em chefes supremos tanto de toda a sua parentela, quanto das parentelas aliadas, podendo sua autoridade transbordar do âmbito local ou regional, ultrapassar o estadual e se apresentar ao nível até nacional. (QUEIROZ, 1976, p. 165).

Ao estruturar sua análise, a autora apresenta vasto estudo sobre a formação e manutenção das parentelas no Brasil. Na pesquisa sobre o norte da Bahia, enfatiza que a população era caracterizada pela homogeneidade, onde cada produtor era dono de seu trabalho e, em geral, dono de sua terra, e isto significava que era conveniente o tratamento do voto como uma mercadoria. Afinal, a troca se estabelecia entre pessoas de um patamar econômico bastante semelhante, proprietários e independentes. Enfatiza também a necessidade de participação dos cabos eleitorais ${ }^{21}$, pois "[...] a importância das relações pessoais comprova que o eleitorado tem possibilidade de escolha”. (QUEIROZ, 1976, p. 167).

Então, tem-se nessa perspectiva, um elemento crucial na discussão sobre o coronelismo. Vitor Nunes Leal considera a dependência pessoal pautada na estrutura agrária desigual do país, que faz com que o eleitor não tenha outra saída para seus problemas senão votar no candidato determinado pelo coronel ao qual se encontra submetido (destituindo o eleitor da capacidade de barganha de seu voto e, mais, ainda, o desvincula de qualquer compreensão da importância política do processo eleitoral como um todo). Já Maria Isaura destaca a prioridade à troca de favores entre iguais (ou quase iguais, do ponto de vista de recursos financeiros), onde cada parte tem clareza da possibilidade de escolha e a noção de qual será o seu benefício se entrar no jogo, isto é, os indivíduos que participam do pacto coronelista o fazem a partir de interesses bem específicos e não como única possibilidade de continuar sobrevivendo segundo recursos provenientes do coronel.

Há que se destacar aqui que a troca de favores também permeia a análise sistêmica do coronelismo. Contudo, a perspectiva de favorecimentos entre iguais (ou, ao menos, entre quem tem

\footnotetext{
${ }^{20}$ Segundo a autora, o termo parentela refere-se a um grupo de pessoas unidas por sangue e por solidariedade, podendo se encontrar em casas diferentes, mas, durante as eleições, toda a família se reúne, hierarquicamente, visando o controle do município, cujo comando e poder ficam com o coronel mais importante da parentela.

${ }^{21}$ Entendido como um pequeno fazendeiro ou comerciante que consegue ser amigo de um grande número de sitiantes, conquistando ou mantendo o eleitorado para seu chefe político.
} 
algo a oferecer) se encontra no vínculo do coronel $^{22}$ "para cima", ou seja, entre o coronel e os agentes políticos que ocupam cargos importantes no estado e não da parte da base da relação, o eleitor. Maria Isaura propõe "racionalidade" no momento de escolha do voto, porque é o momento de convencer o eleitor, e esse processo se expressa no plano da barganha:

O que chamamos de "dom e contra-dom" [sic] se apresenta na realidade como uma reciprocidade ${ }^{23}$ de favores, como que um contrato tácito entre o cabo eleitoral e os eleitores. Estes oferecem seus votos na expectativa de um favor a ser alcançado, podendo o contrato ser rompido quando uma das partes não cumpre o que dela se espera. (QUEIROZ, 1976, p. 168).

De forma oposta a Vitor Nunes Leal, segundo Maria Isaura, o fato dos coronéis terem atividades ligadas ao comércio favoreceu a participação efetiva durante o processo de industrialização, não gerando o fim do coronelismo, mas, acima de tudo, engendrando novas práticas para o fenômeno. Nesse caso, o fato de se ter famílias importantes do Paraná tradicional que ainda ocupam cargos políticos de maior expressão, alguns sobrenomes desde os tempos coloniais, passando pelo contexto imperial e primeiro período republicano, não sinaliza efetivamente que estas se utilizaram de práticas coronelistas após 1930, mas que encontraram mecanismos políticos e econômicos fundamentais para sua sobrevivência, sobretudo firmados numa rede de relações de parentesco, de nepotismo e proteção ${ }^{24}$.

Em Os Donos do Poder (1991), Raymundo Faoro compartilha das principais ideias de Vitor Nunes Leal. Mesmo com o foco no aspecto sistêmico, sua visão assinala substancialmente a presença da violência nas relações do campo (contexto em que o sistema tem sua base de recrutamento). Afinal, em um "[...] contexto de violência, consubstancial à vida rural, ela só se exerce contra o inimigo, nos atentados ao prestígio, em defesa da honra - ficar desmoralizado num conflito equivale à morte”. (FAORO, 1991, p. 634).

\footnotetext{
${ }^{22}$ Vale dizer que, para a autora, o coronel possui autonomia em relação ao poder público, não precisando manter acordo político com essa esfera de poder, tão menos dependência na concessão de seus favores. Ou seja, "[...] o mando político do coronel era resultante de sua posição econômica, em primeiro lugar, que dava ao indivíduo a possibilidade do exercício do poder, colocando-o em situação de 'fazer favores'." (QUEIROZ, 1976, p. 199-200). Contudo, se estabelece algumas indagações: se o coronel não necessitasse de favores de instâncias públicas superiores, qual seria o interesse ao entrar num jogo de manipulação eleitoral (muitas vezes acumulando inimigos ferrenhos no mesmo município)? Qual seria a justificativa para o exercício da barganha dos votos controlados?

${ }^{23}$ Pois, “[...] o fato de se votar num candidato indicado pelo coronel significa que ou o coronel já fez algum benefício ao eleitor, ou deverá fazê-lo; o voto não é inconsciente, muito pelo contrário, resulta do raciocínio do eleitor, e de uma lógica inerente à sociedade à qual pertence”. (QUEIROZ, 1976, p. 168).

${ }^{24}$ Sobre os mecanismos e formas de continuidade das famílias no poder político do Paraná, conferir Ricardo Costa de Oliveira em $O$ silêncio dos vencedores (2001), A construção do Paraná Moderno (2004) e Na teia do Nepotismo (2012).
} 
Assim como Nunes Leal e Carvalho, a barganha se realiza entre os governadores e os chefes políticos locais e não da parte dos coronéis e seus dependentes, ficando marcado o arranjo político de trocas de favores entre iguais (ou quase) apenas de um lado e, de outro, uma relação firmada pela efetiva subordinação ${ }^{25}$. Faoro indica que mesmo nas relações entre os estados e as várias oligarquias, encontram-se posturas autoritárias, já que os estados mais fracos não tinham oportunidade de participar privilegiadamente do jogo político, sendo quase que obrigados (por questões econômicas) a se envolverem de forma subordinada.

Nessa visão, a figura do coronel também é entendida como alguém que se encontra em dificuldades $^{26}$ financeiras, porém, suas dificuldades são mais amenas do que as da grande população, pois “[...] o coronel não manda porque tem riqueza, mas manda porque se lhe reconhece esse poder, num pacto não escrito”. (FAORO, 1991, p. 622). Dessa forma, o seu aparente poder que se coloca perante os miseráveis do campo, por se tornar não só um líder político como também econômico, é condição conferida pelo poder público (governador estadual), através dos favores que recebe ao cumprir sua parte no sistema, aglutinando votos. Então, a função social do coronel, além da garantia de votos, se expressava do mesmo modo no município em lidar com a polícia, com a justiça, com os cobradores de impostos, na tentativa de obter uma estrada, pleitear uma ponte, por exemplo, porque na maioria das vezes o coronel era também o prefeito, ou alguém de sua família ocupava tal cargo.

No artigo Coronelismo e Estado Burguês: elementos para uma reinterpretação (1982), de Décio Saes, tem-se importante análise do coronelismo correlacionada às categorias de análise marxista, em que os conflitos entre as partes são pensados enquanto conflitos de classe. Isto é, tais

[...] observações desencadeiam na análise do coronelismo uma nova problemática teórica: aquela que relaciona as práticas do coronelismo - o poder local - com a unidade contraditória da classe dominante e com o seu organismo político de dominação, o Estado. (SAES, 1982, p. 108).

Segundo o autor, o coronelismo só pode existir inserido num determinado tipo de Estado, o Burguês, com relações de produção pré-capitalistas no campo. Afinal, contribui, ao mesmo tempo, na desorganização dos trabalhadores, impedindo-os de se mobilizarem para reivindicar seus direitos

\footnotetext{
25 "Sobranceiros os chefes ao eleitorado, passivo e inconsciente na soberania das atas falsas e das eleições a bico-depena, libertos de compromissos com os partidos, as decisões políticas obedecem a combinações e arranjos elitários [sic], maquiavélicos. [...] A relação entre a cúpula e a base, em todos os graus, autoritária, sem que o rebanho eleitoral possa reclamar ou negociar, em níveis de comitante [sic] a comissário, o pagamento das promessas". (FAORO, 1991, p. 588). ${ }^{26}$ Assim, questiona-se a perspectiva de Maria Isaura Pereira de Queiroz: como reconhecer uma relação que pressupõe certa igualdade se tal contexto econômico se apresenta num universo onde a maioria da população depende do proprietário rural para sobreviver, mesmo que ele também esteja passando por restrições?
} 
e atacar a propriedade privada, e auxiliando na organização da classe dominante pelo controle e manipulação da via eleitoral, cujo caráter de classe se apresenta oculto.

Pelo fato das massas dependerem economicamente dos proprietários rurais (ainda que não tão abastados), isso resulta na cristalização dos trabalhadores "[...] pela via (específica) da organização/controle do processo eleitoral no campo [itálico do autor]”. (SAES, 1982, p. 113). O coronel participa do processo enquanto intermediário nas relações entre o povo e o Estado, desarticulando os trabalhadores ao tentar amenizar suas dificuldades, não gerando espaço para uma incipiente mobilização e reivindicação no sentido de se alterar as relações de trabalho e suas condições de vida.

Para Saes, a presença do sufrágio universal faz com que o Estado se apresente, aparentemente, como um elemento neutro perante os trabalhadores, pois as relações antagônicas de classe ficam ocultadas na medida em que as eleições são controladas pelos chefes políticos locais, não evidenciando a real dominação burguesa. Até porque, entende que os coronéis, na qualidade de chefes políticos locais estão em declínio e mostram-se ideologicamente como representantes da população e não como peça prioritária do sistema coronelista, que promove a permanência da classe dominante no Estado.

Na obra O coronelismo: uma política de compromissos (1989), de Maria de Lourdes M. Janotti, o coronel $^{27}$ é entendido como alguém de reconhecida autoridade e prestígio, alternando, potencialmente, possibilidades de atender às demandas de sua clientela, sejam públicas ou privadas. O coronelismo seria, então, “[...] o poder exercido por chefes políticos sobre parcelas do eleitorado, objetivando a escolha de candidatos por eles indicados”. (JANOTTI, 1989, p. 07).

Quanto aos trabalhadores rurais, Janotti destaca que eram caracterizados por sua mobilidade entre as propriedades, fazendo com que não se preocupassem em acumular objetos e ter residências mais adequadas, visto que nem mesmo sabiam quanto tempo permaneceriam nas propriedades. "O trabalhador rural se caracteriza muito mais pela sua mobilidade do que por sua fixação num mesmo local”. (JANOTTI, 1989, p. 44). Sendo assim, então, qual seria a garantia para a certeza do controle do voto dos eleitores, se nem ao menos a relação e vínculo de dependência eram estabelecidos?

Em se tratando da periodização do fenômeno, enfatiza que se apresenta posteriormente ao período da Primeira República, se aproximando da concepção de Maria Isaura (além de vários autores que analisam, principalmente, a região nordeste, citados em nota posteriormente), na

\footnotetext{
${ }^{27}$ A autora apresenta vários tipos de coronéis, desde o mais fraco que se encontra no plano municipal até o mais forte, que representa o poder das oligarquias estaduais.
} 
medida em que considera que "[...] diversas manifestações da violência coronelística, por exemplo, podem ser encontradas nos noticiários da imprensa, o que demonstra ser bastante discutível falar-se hoje no fim do coronelismo, mesmo num Estado de economia capitalista”. (JANOTTI, 1989, p. 82).

As discussões sobre o enfoque do coronelismo não se encerram com os autores apresentados, o avanço nas reflexões a respeito do poder local necessita de precisão conceitual. Tal exercício teórico é importante porque cada perspectiva expressa e configura relações políticas e contextos históricos e regionais ${ }^{28}$ específicos. Daí a importância de pesquisas empíricas direcionadas ao coronelismo, tanto em termos estaduais quanto nas análises municipais, conferindo elementos bem precisos de sua prática efetiva, assim como a correlação com instituições políticas importantes do legislativo e também a vinculação direta com o executivo.

\section{ESTRUTURAS FORMAIS DO CORONELISMO}

A organização municipal sempre fez parte da estrutura jurídico-política e administrativa do Brasil, desde a Colônia, passando pelo Império e, redefinindo-se, sistematicamente, durante a Primeira República, num processo de diminuição da autonomia que cabia ao município, tornando-a designada segundo os parâmetros estabelecidos pelo governo estadual. O artigo 68 da Constituição da República dos Estados Unidos do Brasil (de 24 de fevereiro de 1891) expressa: "Os estados organizar-se-ão de forma que fique assegurada a autonomia dos municípios em tudo quanto respeite

\footnotetext{
${ }^{28}$ Para compreender os traços locais e regionais do fenômeno, indicamos as seguintes obras, a exemplo de Goiás: Francisco I. Campos, Coronelismo em Goiás (1987); Luis G. Palacin, Coronelismo no extremo norte de Goiás (1990). Para Pernambuco: Ibarê Dantas, Coronelismo e dominação (1987); André Heráclito do Rêgo, Família e coronelismo no Brasil: uma história de poder (2008). Já no Rio Grande do Sul: Loiva Otero Félix, Coronelismo, borgismo e cooptação política (1987); Márcio A. C. Biavaschi, Relações de poder coronelistas na Região Colonial Italiana do Rio Grande do Sul durante o período borgista (1903-1928) (2011), disponível em: <http://meriva.pucrs.br/dspace/bitstream/10923/3883/1/000430085-Texto\%2BCompleto-0.pdf>, acesso em: 1/08/2015. Para a compreensão do fenômeno no Ceará: Maria Auxiliadora Lemenhe, Família, tradição e poder: o (caso) dos coronéis (1996). Na análise da região nordeste, em geral recomenda-se as seguintes obras: José J. Chiavenato, Cangaço: a força do coronel (1990); P. H. Martins. Coronelismo e dominação burguesa (1983); Maria Auxiliadora Ferraz de Sá, Dos velhos aos novos coronéis (1974); Marcos V. Vilaça e Roberto C. de Albuquerque, Coronel, Coronéis (1988). Para a reflexão do coronelismo em São Paulo: Rodolpho Telarolli, O poder local na República Velha (1977). No estado do Tocantins: M. Emmi, A oligarquia do Tocantins e o domínio dos castanhais (1987). Em se tratando de Santa Catarina: W. F. Piazza, Coronelismo em Santa Catarina (1981). Na Paraíba: Linda Lewin, Política e parentela na Paraíba: um estudo de caso da oligarquia de base familiar (1993). Na Bahia, o clássico de Eul-Soo Pang, Coronelismo e Oligarquias (1889-1942) (1979). E, finalmente, no Paraná, o coronelismo é analisado no seguinte estudo: Mônica H. H. S. Goulart, O poder local e o coronelismo no Estado do Paraná (1880-1930) (2004). Numa perspectiva mais atualizada para o Paraná, ou seja, pós 2004, vale destacar: Alessandro A. Cavassin, Clientelismo eleitoral e coronelismo político, 2006, disponível em: <http://www.justicaeleitoral.jus.br/arquivos/tre-pr-paranaeleitoral-acervos-livro-partidos-politicos-e-eleicoes-clientelismo-eleitoral-e-o-coronelismo-politico>, acesso em: 10/08/2015; Anderson Liscovski, Coronelismo, erva-mate e redes de poder: a elite política de Rio Negro/ PR 18891930 (2007), disponível em: <http://pt.scribd.com/doc/92765791/CORONELISMO-ERVA-MATE-E-REDES-DEPODER-A-ELITE-POLITICA-DE-RIO-NEGRO-PR-1889-1930\#scribd>, acesso em: 10/08/2015.
} 
ao seu peculiar interesse". (BRASIL, 1891, p. 157). Decorrente deste artigo, os estados deveriam definir quais as atribuições e a organização das competências do município. Segundo José de Castro Nunes (1982), este artigo foi consequência de uma emenda apresentada em plenário por Lauro Sodré (em 1891, governador do estado do Pará) e outros constituintes que tinham como principal objetivo construir legalmente maneiras de barrar o poder local num regime político que acabara de se instalar.

No caso do Paraná, o município era declarado como componente de sua unidade administrativa e não de sua unidade política. A primeira Constituição do Paraná, promulgada em quatro de julho de 1891, determinava as condições para a organização municipal sempre no sentido de reforçar sua submissão frente ao governo estadual e, por consequência, ao poder federal. Cumprindo este objetivo, o artigo $54^{29}$ enfatiza a autonomia do município, mas desde que esta autonomia não atingisse as designações do estado, ou seja, uma autonomia municipal relativa, pois se baseava nos limites locais, onde até mesmo poderia ser possível ocorrer intervenção ${ }^{30}$ estadual.

No Paraná, a "restrição" da autonomia municipal, apresentada a partir das leis estaduais, colaborou com o sistema coronelista, proporcionando a troca de favores entre o poder público (cada vez mais fortalecido) e o poder privado. Como exemplo significativo do cerceamento da autonomia municipal, pode-se apontar o caso de uma discussão no Congresso Legislativo em 13 de outubro de 1897, em que o deputado estadual Generoso Marques dos Santos apresentou um projeto de lei cujo conteúdo era fazer com que os municípios publicassem e divulgassem suas "[...] leis, posturas e resoluções [...]" para que estas fossem restringidas à verificação e avaliação do governo estadual, impedindo, necessariamente, possíveis resoluções que afetassem o poder do Estado. Tal projeto, apontado na Ata da $10^{\text {a }}$ Sessão do Congresso Legislativo, de 13 de outubro de 1897, cumpriria, segundo ele, o Artigo 20 da Reforma Constitucional, que seria:

As resoluções ou os atos de administração das autoridades municipais, que infringirem as Constituições ou as leis da União ou do Estado, deverão ser declaradas suspensas pelo Poder Executivo estadual que dará ciência do seu ato ao Congresso Legislativo, o qual em sua primeira reunião resolverá sobre o caso.

\footnotetext{
29 “Art. 54. O Território do Estado será por lei dividido em Municípios, havendo em cada um destes um Conselho Municipal, cuja organização e atribuição terão as seguintes bases: $1^{\circ}$. A municipalidade terá completa autonomia da gestão dos negócios do Município, desde que não ofenda as leis do Estado e da União [grifo nosso] e os direitos do outro Município; $2^{\circ} \mathrm{O}$ Conselho Municipal será eleito por sufrágio, de quatro em quatro anos pelos eleitores do Município; $3^{\circ} \mathrm{O}$ Conselho terá funções deliberativas; $4^{\circ}$ As deliberações do Conselho serão executadas por um ou mais funcionários de sua nomeação, segundo for determinado em lei”. (PARANÁ, 1891, p. 213)
}

${ }^{30}$ Como ocorreu em Ponta Grossa, com o prefeito interventor Brazílio Ribas. (GOULART, 2004; 2014). 
(PARANÁ, 1897, p. 57-58)

Segundo Generoso Marques $^{31}$, a aprovação deste projeto obstruiria, assim, qualquer tentativa de continuidade de abusos que alguns municípios estariam cometendo, pois “[...] é indispensável que os Prefeitos Municipais remetam-lhe toda a legislação municipal vigente, para ele conhecer si algum dos atos dessas municipalidades infringem à Constituição ou as leis federais e estaduais”. (PARANÁ, 1897, p. 58) Mas, é claro que os municípios citados pelo então deputado eram aqueles em que os prefeitos colaboravam com o governo estadual e acabavam recebendo "carta-branca" para suas ações. O fato é, que da apresentação do referido projeto, a oposição faz denúncia a respeito do prefeito de São José dos Pinhais, que estaria usando de autonomia inadequada e ilegal para conseguir arrecadar mais impostos. Generoso Marques, conforme documento apontado anteriormente, coloca o seguinte:

No município de S. José dos Pinhais existe uma lei, que me parece contrária a disposição da lei orgânica municipal, taxando a erva-mate ensacada. (...)

É o caso que o Prefeito reuniu a Câmara, e esta propôs a supressão desse imposto como de outros que lhe pareciam exagerados, e o Prefeito que, pela lei de 1894, não podia presidir a Câmara, expulsou os camaristas recalcitrantes, que haviam assignado a proposta, e declarou que eles haviam perdido os seus lugares por não terem comparecido a duas sessões sucessivas! Por este escândalo, que correu mundo, os contribuintes tiveram notícia desta lei; mas esperavam que fossem notificados do imposto para se defenderem do pagamento de uma taxa ilegal. Alguns desses contribuintes transportaram para esta Capital a sua erva-mate em carroças e, passando pela vila de São José dos Pinhais, foram surpreendidos pela apreensão dessas mercadorias, a titulo de garantia ao pagamento do imposto. Requereram ao Prefeito que lhes mandasse certificar qual a disposição legal em que se tinha fundado aquele ato de apreensão.

Sabe V. Ex., Sr. Presidente, qual foi o despacho do Prefeito? "Pague e volte". (PARANÁ, 1897, p. 58)

Ainda nesta questão, é válido enfatizar que os dois camaristas expulsos eram da oposição (do grupo de Generoso Marques), ficando evidente que, também enquanto prefeitos locais, os coronéis usavam de sua pretensa legalidade, quando apoiado ou camuflado pelo governo estadual, para garantir seus interesses. Para o caso citado anteriormente, o prefeito de São José dos Pinhais (cel. Norberto Alves de Brito - nomeado pelo executivo estadual) era vinculado partidariamente ao então governador Francisco Xavier da Silva (do grupo de Vicente Machado).

Se levarmos em conta que os prefeitos que representavam os governos municipais eram

${ }^{31}$ Conforme seus dizeres apresentados na mesma Ata da $10^{\mathrm{a}}$ Sessão do Congresso Legislativo, de 13 de outubro de 1897. (PARANÁ, 1897, p. 58) 
responsáveis por sua administração e também pela indicação e distribuição de diversas funções e cargos, ainda na década de 1920, muitos municípios paranaenses destacam em seu corpo administrativo os mesmos sobrenomes, ou seja, pertencem às mesmas famílias, compondo a lista de funcionários como camaristas, juízes, tabeliães e até mesmo de prefeitos, sendo os próprios coronéis, quando não seus parentes próximos.

Assegurando o sistema coronelista, o acesso aos favores para os coronéis e seus familiares era um dos objetivos deste pacto, onde até mesmo os salários colocavam-se como essenciais na garantia financeira e no prestígio local no município frente à grande massa da população. Nesse sentido, durante a década de 1920, tem-se o exemplo de famílias de coronéis que ocupavam ao mesmo tempo os principais cargos públicos (prefeitura, vice-prefeitura, vereança, tabeliães, tesoureiros, presidência de câmara municipal, procurador, delegado de polícia, suplente de delegado) em seus respectivos municípios, tais como: a família do cel. Tertuliano de Almeida Faria, no município de São Mateus do Sul; em Guarapuava, a família do cel. Pedro Amaral; no município de Colombo, a família do cel. José Leal Fontoura; em Campina Grande do Sul, os familiares do cel. Feliciano Ribeiro; em Tibagi era a família do cel. Frederico Mascarenhas Martins; em Teixeira Soares, a família do cel. João Ribeiro de Macedo; em Mallet, familiares do cel. Antônio Sá; em Campo Largo, a família do cel. César Torres; em São João do Triunfo, a família do cel. Pedro Ferreira de Andrade ocupava os principais cargos no município. (GOULART, 2004; CAPRI \& OLIVERO, 1923).

Nesse contexto, o deputado Cel. Telêmaco Morcines Borba ${ }^{32}$ chegou a apresentar na Assembleia Legislativa do Paraná, na $14{ }^{\text {a }}$ Sessão Ordinária, em 16 de fevereiro de 1911, um projeto que visava regular os pedidos de licença dos funcionários públicos, já que estes usavam regularmente licenças de quatro meses, então, deveriam comparecer a uma junta médica para comprovar a real necessidade de afastamento. Apesar do projeto não ser aprovado e, é claro, por razões bem claras, o Cel. Telêmaco Borba denunciou em plenário que somente um dos deputados da casa teria quatorze sobrinhos como funcionários públicos. (PARANÁ, 1911, p. 48).

A dependência financeira do município perante o governo paranaense manifestava-se de maneira eficaz. As Atas da Assembleia Legislativa do Paraná apresentam uma série de projetos em que os representantes do poder local, em sua maioria deputados que eram coronéis (e, muitas vezes de forma simultânea, também prefeitos) pediam auxílio de recursos financeiros às câmaras municipais, como ocorre em 1895 para o município de Guarapuava para melhoramentos locais, conforme o projeto n. 35 da Ata da $25^{\text {a }}$ Sessão, em 12 de dezembro de 1895. (PARANÁ, 1895, p. 131). Em data

32 Para a biografia do cel. Telêmaco Morcines Borba, conferir a obra de Ana C. Vanali, O Botocudo Tibagyano: análise sobre os registros etnográficos de Telêmaco Borba (2013). 
próxima, o município de Curitiba também requer auxílios para realização de benfeitorias locais segundo a Ata da $29^{\text {a }}$ Sessão, em 17 de dezembro de 1895 (PARANÁ, 1895, p. 150), assim como também o pedido para o município de Colombo ${ }^{33}$, Ata da $31^{\text {a }}$ Sessão, em 20 de dezembro de $1895^{34}$. (PARANÁ, 1895, p. 156)

Uma das práticas recorrentes ao coronelismo da Primeira República era a utilização de verbas públicas para firmar aos coronéis o reconhecimento de seu poder local e prestígio por parte dos eleitores. Assim, as benfeitorias nos municípios deveriam partir dos recursos do estado, mas o acordo só se realizava se o coronel estivesse ligado à situação política. Nesse sentido, a Ata da $13^{\text {a }}$ Sessão do Congresso Legislativo, de 15 de fevereiro de 1911, apresenta um pedido do cel. César Torres onde este recorre aos aliados do executivo para liberação de verbas para a construção de uma ponte em Campo Largo. Demanda que foi rapidamente discutida e aceita, principalmente a partir da justificativa colocada por tal coronel:

Entretanto, basta um só dia de chuva para interromper a passagem aí, com grande prejuízo do público. Até tem se dado o fato de eleitores que moram do outro lado do rio, não poderem comparecer às urnas em dia de eleição quando ainda não há muito aconteceu com mais de 90 eleitores, que não puderam passar para votar na eleição de Presidente da República. (PARANÁ, 1911, p. 140)

\section{Conforme expõe Rodolpho Telarolli, em Eleições e Fraudes Eleitorais na República Velha} (1982), a análise formal, do ponto de vista da legislação eleitoral, não corresponde à totalidade das práticas eleitorais na Primeira República. Se por um lado, se dispunha de leis e regulamentos legitimando as eleições, por outro, havia as realizações práticas, cotidianas e informais, que acabavam determinando seu resultado, tendo na figura do coronel um dos principais protagonistas.

No Paraná, os espaços para a realização das eleições eram divulgados pelo jornal A República, indicando o endereço das respectivas sessões de votação. A partir da listagem apresentada na edição do jornal de 9 de outubro de 1894, verifica-se, por exemplo, que 35,7\% dos locais de votação eram residências particulares ${ }^{35}$ e, muitas delas, propriedades de correligionários e de pessoas ligadas aos

\footnotetext{
${ }^{33}$ Interessante que a justificativa para tal pedido passa pelo fato de que a câmara de Ponta Grossa já havia recebido o mesmo tipo de benefício: “[...] A Câmara Municipal da Vila de Colombo em representação dirigida ao Congresso do Estado pede que, a exemplo de Ponta Grossa, se passe a mesma Câmara, como auxílio as suas rendas, a dívida colonial do seu município". (PARANÁ, 1895, p. 156)

${ }^{34}$ Durante discussão no Congresso Estadual, revelada na Ata da $26^{\mathrm{a}}$ Sessão, de 14 de fevereiro de 1895 , o deputado estadual Ventura Torres aponta a provável denúncia: "Orava o Sr. J. Loyola justificando seu projeto, quando eu dei-lhe um aparte, referindo-me aos muitos favores que a Câmara de Antonina tem recebido do Governo”. (PARANÁ, 1895, p. 140)

${ }^{35}$ Dentre os locais, o palacete do cel. Francisco Brito, situado na Praça da Proclamação, em Curitiba. A família Brito era bastante importante no Paraná, sendo ligada por casamento, à família do cel. Joaquim Lacerda, chefe político da
} 
chefes políticos locais. Fato que, por si só, poderia gerar alguma forma de constrangimento ou, ao menos, coação para com um possível eleitor oposicionista. (Eleição, 1894, p. 1-2)

\section{PODER POLÍtico, PRÁticas ELEITORAIS E SISTEMA CORONELISTA NO PARANÁ}

Diferentemente de estados como Bahia, Pernambuco, Ceará, São Paulo e Rio Grande do Sul, por exemplo, o Paraná não teve coronéis com expressão política nacional, até porque não tiveram poder suficiente para alcançar o primeiro plano do executivo estadual. Assim, a lista de nomes que compõem o governo ${ }^{36}$ do estado indica que os coronéis paranaenses raras vezes chegaram ao executivo, tão somente como substitutos (fato que não lhes conferia grande poder político), enquanto $1^{\mathrm{o}}$ e $2^{\mathrm{o}}$ vice-governadores: cel. Joaquim José Alves ${ }^{37}$ (no Império, vice-governador 03/09/1889 a 11/09/1889) e cel. João de Menezes Dória ${ }^{38}$ (presidente durante o governo revolucionário - 21/01/1894 a 24/03/1893). Contudo, os coronéis paranaenses sempre procuraram manter-se ligados aos partidos, antes e após 1908. Quanto ao Senado, não se pode dizer que algum coronel tenha ocupado tal cargo político. No que se concerne ao Congresso Federal, percebe-se uma pequena abertura com os seguintes nomes: João de Menezes Dória (03/05/1906 a 31/12/1908); cel. Luiz Antônio Xavier ${ }^{39}$ em três mandatos, (03/05/1912 a 31/12/1914; 03/05/1915 a 31/12/1917; 03/05/1918 a 31/12/1917); cel. Eurides Cunha ${ }^{40}(03 / 05 / 1924$ a 31/12/1926; 03/05/1927 a 23/10/1930); e o cel. Ottoni Ferreira Maciel, somente uma única vez (03/05/1918 a 31/12/1920). (FERREIRA, 1999). Entretanto, se comparado com a presença de apenas quatro coronéis, num total de sessenta e quatro cadeiras (entre 1880-1930, período da pesquisa original), a representatividade passa a ser ainda menos significativa. $\mathrm{O}$ que se fez comum quanto à ocupação de cargos públicos

Lapa, além de ocuparem cargos nas Secretarias de Governo. (DICIONÁRIO HISTÓRICO-BIOGRÁFICO DO ESTADO DO PARANÁ, 1991, p. 243; GOULART, 2015).

${ }^{36}$ Governadores eleitos no referido período: Generoso Marques, Francisco Xavier da Silva, José Pereira dos Santos Andrade, Vicente Machado, João Cândido Ferreira, Carlos Cavalcanti, Afonso Camargo e Munhoz da Rocha. (GOULART, 2004; 2014).

${ }^{37}$ Deputado provincial, chefe político em Morretes, ainda no Império. (NICOLAS, 1984, p. 185).

${ }^{38}$ Médico e importante político (oposicionista), aliado às forças federalistas. (NICOLAS, 1984, p. 282).

${ }^{39}$ Ocupou vários cargos políticos importantes em Curitiba (Prefeitura, Secretaria). Irmão do cel. João A. Xavier, liderança política de Paranaguá. Ambos correligionários de Vicente Machado. (NICOLAS, 1984; GOULART, 2014).

40 Chefe político de Jaguariaíva, proprietário da Fazenda Samambaia, presidente do diretório municipal do PRPr. Prefeito de Curitiba em 1928-1930. (GOULART, 2004). 
era o fato dos coronéis paranaenses ocuparem as prefeituras municipais e, quando possível, alternando-as como deputados estaduais na ALEP, tais como: o cel. Telêmaco Borba (prefeito de Tibagi); cel. Amazonas de Araújo Marcondes (prefeito de União da Vitória); cel. Lysandro Alves de Araújo (prefeito de Entre Rios); cel. Theóphilo Soares Gomes (prefeito de Antonina); cel. Feliciano Ribeiro (prefeito de Campina Grande); cel. César Torres (prefeito de Campo Largo); cel. Domingos Teodorico de Freitas (prefeito de Palmeira); cel. Ernesto Marcondes Carneiro (prefeito de Piraí); cel. Brasílio Ribas (prefeito de Ponta Grossa); cel. Ernesto Marcondes Carneiro (prefeito de Piraí); cel. Theóphilo Fabiano Cabral e cel. João Cândido de Oliveira (ambos, prefeitos de Almirante Tamandaré, nas décadas de 1920 e de 1910, respectivamente); cel. Carlos Pioli (prefeito de Rio Branco do Sul), entre outros. (GOULART, 2004).

Outro aspecto definidor do sistema coronelista no Paraná era a importância do vínculo partidário, ou seja, estar agregado a um dos partidos políticos servia para a ocupação de cargos públicos eletivos, não somente como vínculo político e recursos financeiros, mas também se reafirmava na organização do próprio sistema coronelista: de um lado, os coronéis se convertiam em poderosos locais através do estatuto político que lhe era repassado pelo partido ${ }^{41}$ e, de outro, conseguiam manter no executivo estadual os grupos mais dominantes, através da certeza do controle do eleitorado.

Assim, tanto o PR e o PRF, como principalmente o PRPr, foram instrumentos políticos e partidários disciplinadores, essenciais para o estabelecimento e para a continuidade do sistema coronelista no período. E também, ao mesmo tempo, cumpriam o papel de reproduzir a subordinação do poder local ao governo estadual, refletindo, por excelência a fraqueza e dependência dos coronéis para com o poder público estadual.

O sistema político partidário da Primeira República era eminente na sustentação das oligarquias estaduais, pois a ausência de partidos nacionais contribuiu sobremaneira para o fortalecimento dos grupos estaduais, que disputavam as eleições para terem assegurados os representantes nas esferas de poder municipal, estadual e federal. No Paraná, antes da Coligação Partidária $^{42}$ a disputa eleitoral se conjugava prioritariamente ${ }^{43}$ entre o PRF e o PR. Mas foi com o

\footnotetext{
41 A disciplina partidária e a hierarquia de poder entre o Diretório Central (Comissão Executiva) e os diretórios municipais também são elementos do sistema coronelista, pois reproduz a relação existente entre ambas as esferas de poder. No Paraná, os nomes que aparecem como representantes do Diretório Central dos Partidos (antes e depois de 1908) são aqueles que estão à frente do executivo estadual e concentram maior poder político no estado, já os coronéis eram os representantes dos diretórios municipais. Conferir, para este caso, os anexos e apêndices de GOULART (2004).

${ }^{42}$ Com a morte de Vicente Machado em 1907 (que era o político de maior expressão e poder), as lideranças partidárias estabeleceram a Coligação Partidária, em 1908, que decorreu de um pacto político firmado com o objetivo de unir dois dos partidos políticos que disputavam, até então, as eleições. Assim, as principais lideranças definiram as próximas eleições, assim como também a distribuição dos cargos mais importantes no estado. Tão logo a aglutinação ocorreu, o
} 
PRPr que consolidou-se o controle dos diretórios municipais ${ }^{44}$ por parte dos coronéis, tornando-se instrumento ainda mais eficaz para o controle das eleições.

Quanto às eleições, o Paraná também retratou inúmeros tipos e possibilidades de fraudes eleitorais, que envolviam diretamente os coronéis e, indiretamente, os governadores, na medida em que fechavam os olhos para as irregularidades locais ou, então, se sobrepunham, por meio do aparato policial, aos pretensos opositores. Os jornais da época e as atas da ALEP relatam a presença de fraudes de toda ordem, inclusive os momentos quando a violência física ocorria por meio de tiroteios e esfaqueamentos. Os assassinatos durante as eleições não eram fatos esporádicos, relatos desse tipo se encontram em todo período estudado. (GOULART, 2004; 2014).

Entre os principais aspectos rotineiros tem-se: realização de eleições às escondidas, onde compareciam às urnas somente eleitores escolhidos ${ }^{45}$; pedidos de escolta policial ao governo do estado para acompanhamento das eleições, ocorrendo violência aos eleitores oposicionistas e prisões aos que teriam votado no candidato "errado"6"; os capangas dos coronéis disparavam tiros para "correção" do voto do eleitorado ${ }^{47}$; alistamento eleitoral feito criminosamente, uma vez que o filho do escrivão fabricava eleitores para facção do chefe político local ${ }^{48}$; número de votos muito

poder político continuou concentrado, mas agora nas mãos do ex-oposicionista Afonso Alves de Camargo. (GOULART, 2004; 2014).

${ }^{43}$ Uma análise detalhada do sistema político partidário do Paraná entre os anos 1889-1930 demonstrará que em períodos específicos existiram outros arranjos políticos e agremiações partidárias. Todavia, eram formadas por membros que passaram pelos partidos citados, assim como também não conseguiam obter sustentação política por tempo significativo às disputas eleitorais. (GOULART, 2014).

\footnotetext{
${ }^{44}$ Numa investigação a partir do Album do Paraná, de CAPRI \& OLIVEIRO (1923), pode-se indicar coronéis que eram representantes municipais do Partido Republicano Paranaense e, ao mesmo tempo, exerciam o cargo de prefeitos municipais, tais como: em Bocaiuva, cel. Gordiano Dias de Almeida Baptista; Castro, cel. Antonio Rolim de Moura; Clevelândia, Dr. Piragibe de Araújo; Conchas, cel. Cipriano Gomes da Silveira; Entre Rios, cel. Lysandro Alves de Araújo; Imbituva, cel. Silvério de Miranda; Ipiranga, cel. João Ribeiro de Freitas; Jaguariaíva, cel. Eurides Cunha; Marumbi, cel. Joaquim Luiz dos Santos; Palmas, cel. Domingos Soares; Paranaguá, cel. José Gonçalves Lobo; Piraí, cel. Ernesto Marcondes Carneiro; Rio Negro, cel. Felipe Kichner; São João do Triunpho, cel. Agostinho Ribeiro Macedo Lima; São Mateus, cel. Tertuliano de Almeida Faria; Tibagi, cel. Frederico Mascarenhas Martins; e por fim, em União da Vitória, cel. Amazonas de Araújo Marcondes. (GOULART, 2004, p. 201).

${ }^{45}$ Ata da $20^{\text {a }}$ Sessão Ordinária do Congresso Legislativo de Estado do Paraná, em 26 de outubro de 1897. (PARANÁ, 1897, p.106-111)

${ }^{46}$ Ata da $28^{\text {a }}$ Sessão do Congresso Legislativo do Estado do Paraná, em 8 de outubro de 1897. (PARANÁ, 1897, p. 157-161)

${ }^{47}$ Situação ocorrida em Curitiba e no município de Rio Negro. (O pleito. 1900, p. 1)

${ }^{48}$ Caso ocorrido nos distritos do município de Tibagi: São Jerônimo, Jatahy, Reserva e Caetê. (Fazendo Eleitores, 1924, p. 5)
} 
superior ao de eleitores $\operatorname{comparecidos}^{49}$; ameaças de demissão do serviço público caso os funcionários municipais votassem na oposição ${ }^{50}$, entre outros.

As trocas de favores entre o poder privado e o poder público consolidavam-se como mecanismo de manutenção do sistema. No presente caso, são efetivadas ao longo das sessões da ALEP, uma vez que seus membros apresentavam projetos que beneficiavam diretamente os representantes do poder local, ou, então, falavam em seu próprio nome, enquanto deputados coronéis. Vale ressaltar alguns relatos: permissão ao cel. Ignácio de Araújo Pimpão (de Palmas) ou à empresa que organizar futuramente, no prazo de $60 \operatorname{anos}^{51}$, para “[...]isenção de direitos estaduais de importação de trigo em grãos e de maquinismos destinados ao moinho do cidadão Ignácio de Paula França, durante o prazo de $10 \operatorname{anos}^{52}$, , pedido de aumento dos vencimentos do cel. Teophilo Soares Gomes, já que passou a exercer também o cargo de fiscal do Banco de Curitiba ${ }^{53}$; além de inúmeros projetos aprovados que tinham como objetivo único conceder favores (expressão efetivamente utilizada) tanto às pessoas (geralmente os coronéis municipais, ou seus parentes) ou para municípios, em particular. (GOULART, 2004; 2014).

\section{CONSIDERAÇÕES FINAIS}

Contrariando estudos que compartilham a ideia de grandes coronéis na figura de líderes da política nacional, o presente estudo indica que os coronéis paranaenses tiveram seu poder político limitado ao contexto municipal. Assim, entendemos que o coronelismo paranaense envolveu contornos gerais do sistema coronelista brasileiro tal como descrito por Vitor Nunes Leal, destacando que o coronel participa de um compromisso político por estar em sua base, ou seja, por

\footnotetext{
${ }^{49}$ Município de Guarapuava. (Como é isso? 697 votos deu Guarapuava nas eleições de 31 de outubro! O Sr. Romualdo Baraúna em foco. 1921, p.1) Relato semelhante para as eleições no município de União da Vitória (Química eleitoral, 1900, p.1)

${ }^{50}$ Crítica aos abusos do poder político exercido pelo então governador do estado, Afonso Camargo. (As eleições, 1921, p.1) Situação próxima aos fatos ocorridos na capital curitibana. (As eleições estaduais: a pressão do governo,1919, p.1)

${ }^{51}$ Segundo a Ata da $38^{\text {a }}$ Sessão Ordinária do $1^{\circ}$ Ano da $15^{a}$ Legislatura, em 16 de março de 1920, Aníbal Requião, tio avô por parte de mãe do ex-governador Roberto Requião, também obteve concessão de 60 anos para construção de estrada de bitola que passava por Curitiba e redondezas. (PARANÁ, 1920, p. 661, 662)

${ }^{52}$ Conforme Ata da $6{ }^{\text {a }}$ Sessão Ordinária do Congresso Legislativo do Estado do Paraná, em 20 de novembro de 1895. (PARANÁ, 1895, p. 30). Ignácio de Paula França era um dos cidadãos que abriam suas casas para realização das eleições em 1900. Também ocupou o cargo de Prefeito Interino de Curitiba, em 1897, durante o governo de José Pereira dos Santos Andrade, vinculado ao partido vicentista. (GOULART, 2004; 2014)

53 Conforme consta na Ata da $24^{\mathrm{a}}$ Sessão Ordinária do $1^{\mathrm{o}}$ ano da $15^{\mathrm{a}}$ Legislatura, em 28 de fevereiro de 1920. (PARANÁ, 1920, p. 556)
} 
controlar os votos da massa da população rural e, mais ainda, por conseguir mantê-la submissa e fragmentada. (LEAL, 1986; SAES, 1982).

Apesar das Constituições (1891, 1892, 1927) paranaenses apresentarem passagens enfatizando aspectos de autonomia municipal, esta era sempre definida segundo parâmetros do executivo estadual, já que a autoridade do chefe político local era efetivamente submissa e limitada à autoridade maior dos representantes do governo estadual. Daí o aspecto a que Nunes Leal chama a atenção para o estudo do coronelismo, sua existência condicionada enquanto "[...] fruto de alteração de forças entre proprietários rurais e o governo e significava a fortalecimento do poder do estado antes que o predomínio do coronel”. (CARVALHO, 1997, p. 231).

Com relação à dependência política do homem do campo e sua fidelidade em relação ao coronel, representando a base do sistema, firmava-se pelas condições de vida precária, pela escassez de recursos básicos e pelo analfabetismo, por exemplo. Ora, se a fidelidade do elemento do campo não existisse, não poderíamos verificar o controle do voto por parte dos chefes políticos locais, não encontraríamos trocas de favores entre representantes do governo e os coronéis, não seria possível verificar um partido capaz de lançar 30 deputados para a ALEP e esses mesmos deputados serem todos eleitos, e nem mesmo teria sido necessária a união de dois partidos antagônicos, para terem asseguradas as eleições e seus resultados. Acima de tudo, não seria notório o repasse de verbas e favores para diversas prefeituras e chefes políticos locais, pois o próprio governo não direcionaria verbas públicas em momentos em que o orçamento estadual estivesse negativo, se isso não fizesse parte do jogo.

\section{REFERÊNCIAS}

BIAVASCHI, M. A. C. Relações de poder coronelistas na Região Colonial Italiana do Rio Grande do Sul durante o período borgista (1903-1928). (2011). Disponível em: <http://meriva.pucrs.br/dspace/bitstream/10923/3883/1/000430085-Texto\%2BCompleto-0.pdf. Acesso em: 01/08/2015.

CAMPOS, F. I. Coronelismo em Goiás. Goiânia: Editora UFG, 1987.

CAPRI \& OLIVERO, Estado do Paraná. São Paulo: Empresa Editora Brasil, 1923.

CARVAlHO, J. M. de. Cidadania no Brasil: o longo caminho. 5. ed. Rio de Janeiro: Civilização Brasileira, 2004. 
Mandonismo, coronelismo, clientelismo uma discussão conceitual. Dados - Revista de

Ciências Sociais, Rio de Janeiro, v. 40, n. 2, p. 229-250, 1997.

CAVASSIN, A. A. Clientelismo eleitoral e coronelismo político. In: CODATO, A. N.; SANTOS, F. J. dos. (Orgs.). Partidos e eleições no Paraná: uma abordagem histórica. Curitiba - PR: Tribunal Regional Eleitoral do Paraná (TRE-PR), 2006. Disponível em: <http://www.justicaeleitoral.jus.br/arquivos/tre-pr-parana-eleitoral-acervos-livro-partidos-politicose-eleicoes-clientelismo-eleitoral-e-o-coronelismo-politico>. Acesso em: 30/07/2015.

CHIAVENATO. J. J. Cangaço: a força do coronel. São Paulo: Brasiliense, 1990.

DANTAS, I. Coronelismo e dominação. Pernambuco: PROEX/CECAC Programa Editorial, 1987.

DICIONÁRIO HISTÓRICO-BIOGRÁFICO DO ESTADO DO PARANÁ. Paraná: Chain, Banestado, 1991.

DOMINGUES, J. M. Patrimonialismo e Neopatrimonialismo. In: AVRITZER, L. et al. (Org.). Corrupção: ensaios e críticas. Belo Horizonte: Editora UFMG, 2008.

EMMI, M. A oligarquia do Tocantins e o domínio dos castanhais. Belém: Centro de Filosofia e Ciências Humanas/NAEA/UFPA, 1987.

FAORO, R. Os donos do poder. 9. ed. 2 v. São Paulo: Editora Globo, 1991.

FÉLIX, L. O. Coronelismo, borgismo e cooptação política. Porto Alegre: Mercado Aberto, 1987.

GOULART, M. H. H. S. A dança das cadeiras: análise do jogo política na Assembleia Legislativa do Paraná (1889-1930). Jundiaí: Paco Editorial, 2014.

O poder local e o coronelismo no Estado do Paraná (188-1930). 232 p. Dissertação. (Mestrado em Sociologia) - UFPR, Curitiba, 2004. Disponível em: <http://dspace.c3sl.ufpr.br/dspace/bitstream/handle/1884/11747/Folha\%20de\%20Rosto\%20Disserta \%C3\%A7\%C3\%A3o.pdf? sequence=2>. Acesso em: 12/08/2015. 2015.

Entre Famílias e Secretarias: análise do arranjo político administrativo do Paraná (18891930). In: OLIVEIRA, R. C. de. (Org.). Estado, classe dominante e parentesco no Paraná. Blumenau: Nova Letra, 2015. 
GRAHAM, R. Clientelismo e política no Brasil do século XIX. Rio de Janeiro: Editora UFRJ, 1997.

JANOTTI, M.L. M. O coronelismo: uma política de compromissos. São Paulo: Brasiliense, 1989. (Coleção Tudo é História).

LEAL, V. N. Coronelismo, enxada e voto: o município e o regime representativo no Brasil. 5. ed. São Paulo: Alfa-Ômega, 1986.

LEMENHE, M. A. Família, tradição e poder: o(caso) dos coronéis. São Paulo: Annablume, 1996.

LEWIN, L. Política e parentela na Paraíba: um estudo de caso da oligarquia de base familiar. Rio de Janeiro: Record, 1993.

LISCOVSKI, A. Coronelismo, erva-mate e redes de poder: a elite política de Rio Negro/PR 1889-1930 (2007). Disponível em: <http://pt.scribd.com/doc/92765791/CORONELISMO-ERVAMATE-E-REDES-DE-PODER-A-ELITE-POLITICA-DE-RIO-NEGRO-PR-1889-1930\#scribd>. Acesso em: 10/08/2015.

MARTINS, P. H. N. Coronelismo e dominação burguesa. Symposiun - Revista da Universidade Católica de Pernambuco, Recife, v. 25, n. 2, p. 29-38, 1983.

NICOLAS, M. 130 Anos de vida parlamentar (1854-1984). Curitiba: Arquivo da Assembleia Legislativa do Paraná, 1984.

NUNES, J.C. Do Estado Federado e sua organização municipal. Brasília: Câmara dos Deputados, 1982.

Apêndice: Organização municipal dos Estados (Legislação), 1920. In: Do Estado Federado e sua organização municipal. Brasília: Câmara dos Deputados, 1982.

OLIVEIRA, R. C. de O silêncio dos vencedores: genealogia, classe dominante e Estado no Paraná. Curitiba: Moinho do Verbo, 2001.

Na teia do Nepotismo: Sociologia das relações de parentesco e o poder político no Paraná e no Brasil. Curitiba: Insight, 2012. 
. (Org.). A construção do Paraná Moderno: políticos e política no governo do Paraná de 1930 a 1980. Curitiba: SETI, 2004.

PALACIN, L. G. Coronelismo no extremo norte de Goiás. São Paulo: Loyola, 1990.

PANG, E. Coronelismo e oligarquias (1889-1942). Rio de Janeiro: Civilização Brasileira, 1979.

PIAZZA, W. F. Coronelismo em Santa Catarina. Roteiro - Fundação Educacional do Oeste Catarinense. Joaçaba, v. 2, n. 6, p. 25-30, 1981.

QUEIROZ, M. I. P. de. O coronelismo numa interpretação sociológica. In: . Mandonismo local na vida política brasileira e outros ensaios. São Paulo: Alfa-Ômega, 1976.

RÊGO, A. H. do. Família e Coronelismo no Brasil: uma história de poder. São Paulo: A Girafa, 2008.

SÁ, M. A. F. de. Dos velhos aos novos coronéis. Recife: PIMES, 1974.

SAES, D.A. M. de. Coronelismo e Estado burguês: elementos para uma reinterpretação. Nova Escrita Ensaio, São Paulo, v. 4, n. 9, 1982, p. 107-127.

TELAROLLI, R. Eleições e fraudes eleitorais na República Velha. Rio de Janeiro: Brasiliense, 1982. (Coleção Tudo é História).

O poder local na República Velha. v. 364. São Paulo: Brasiliana, 1977.

VANALI, A. C. O Botocudo Tibagyano: análise sobre os registros de Telêmaco Borba. Curitiba: SAMP, 2013.

VILAÇA, M. V.; ALBUQUERQUE, R. C. de. Coronel, coronéis. 3. ed. Rio de Janeiro: Tempo Brasileiro; Niterói: Universidade Federal Fluminense/ EDUFF, 1988.

\section{DOCUMENTOS HISTÓRICOS}


PARANÁ. Anais do Congresso Legislativo do Estado do Paraná. Curitiba: Tipografia D’ A República, 1895.

Anais do Congresso Legislativo do Estado do Paraná. Curitiba: Tipografia D' A República, 1897.

Anais do Congresso Legislativo do Estado do Paraná. Curitiba: Tipografia D' A República, 1911.

Anais do Congresso Legislativo do Estado do Paraná. Curitiba: Tipografia D' A República, 1920.

CONSTITUIÇÕES:

BRASIL. Constituição (1891). Constituição da República dos Estados Unidos do Brasil, 1891. In: BRIGAGÃO, Clóvis; SILVA, Raul Mendes. (Orgs.). História do Poder Legislativo do Brasil. Rio de Janeiro: Editora Multimídia, 2003.

PARANÁ. Constituição (1891). Constituição do Estado Federado do Paraná. Leis e Decretos do Estado do Paraná. Curitiba, 1890-1891.

Constituição (1892). Constituição do Estado Federado do Paraná. Anais do Congresso Legislativo do Estado do Paraná. Curitiba: Tipografia A República, 1892.

Constituição (1927). Constituição do Estado Federado do Paraná. Publicação Oficial. Curitiba: Livraria Mundial França \& Cia, 1927.

JORNAIS:

As eleições. Gazeta do Povo, Curitiba, 21/02/1921, n. 631, p.1.

As eleições estaduais: a pressão do governo. Gazeta do Povo, Curitiba, 20/10/1919, p.1. 
Como é isso? 697 votos deu Guarapuava nas eleições de 31 de Outubro! O Sr. Romualdo Baraúna em foco. Gazeta do Povo, Curitiba, 08/12/1921, n. 875, p.1.

Eleição. A República, Curitiba,09/10/1894, n. 128, p.1-2.

Fazendo Eleitores. Gazeta do Povo, Curitiba, 16/04/1924, p. 4.

O Pleito. A República, Curitiba, 03/01/1900, n.1, p.1.

Química eleitoral. A República, Curitiba, 10/01/1900, n. 6, p.1.

\title{
LOCAL AND CORONELISMO POWER IN PARANÁ
}

\begin{abstract}
This article aims to analyze the coronelismo phenomenon in the state of Paraná in the years 1880-1930. It was noticed that the Paraná coronelismo occurred from the perspective of Victor Nunes Leal, who considers it from the systemic relationship favors exchange between representatives of private power, so-called colonels (weakened), and the government, state governors (increasingly strengthened). For the colonel, the assurance of his position was given by the control of the votes of the poor and dependent population, most of which was in the countryside. The key to the understanding of such phenomena is present by mapping their formal structures, the disciplinarian partisan political power arrangement and illegal practices during elections, as well as analysis of trade favors involving such a system. To
\end{abstract}


develop the research, we used to study various aspects of the theme, for example, the theoretical discussion about the very concept of coronelismo and empirical research through various sources such as newspapers, state constitutions and minutes of the Paraná Legislative Assembly.

Keywords: Coronelismo. Paraná. First Republic. 